\title{
Family System Functioning in Caring for Thai Survivors with Severe Traumatic Brain Injury
}

\author{
Sumamita Sawasdinaruenart, M.N.S. ${ }^{1}$, Warunee Fongkaew, Ph.D. ${ }^{2}$, Praneed Songwathana, Ph.D. ${ }^{3}$, \\ Hilaire J. Thompson, Ph.D. ${ }^{4}$, Nuttamon Vuttanon, Ph.D. ${ }^{5}$, Chanchai Yothayai, Ph.D. ${ }^{5}$ \\ ${ }^{1}$ Faculty of Nursing, Chiang Mai University, Mueang, Chiang Mai 50200, Thailand. \\ 2Department of Medical Nursing, Faculty of Nursing, Chiang Mai University, Mueang, Chiang Mai 50200, Thailand. \\ ${ }^{3}$ Department of Adult and Elderly Nursing, Faculty of Nursing, Prince of Songkla University, Hat Yai, Songkhla 90110, Thailand. \\ ${ }^{4}$ School of Nursing, University of Washington, Seattle, Washington 98195-7260, The United States of America. \\ ${ }^{5}$ Department of Surgical Nursing, Faculty of Nursing, Chiang Mai University, Mueang, Chiang Mai 50200, Thailand. \\ Received 11 June 2020 • Revised 7 August 2020 • Accepted 8 August 2020 • Published online 30 December 2020
}

\section{Abstracts:}

Objective: This study aimed to describe family system functioning, in providing care for a family member, after surviving a severe traumatic brain injury (TBI).

Material and Methods: A cross sectional survey, using a self-report questionnaire, was conducted with 77 family members; from 32 families, caring for survivors from one province in southern Thailand. Family system functioning was measured using the Family Assessment Measure III (FAM-III) General Scale, Thai version as well as a demographic questionnaire. Descriptive statistics were applied to analyze family functioning including means, standard deviation, percentage and T-scores.

Results: The findings showed that the overall family system functioning existed within the moderate level (M=49.94, S.D. =8.99). The finding also indicated moderate levels of functioning within the FAM III subscales.

Conclusion: The present findings provide evidence that family systems functioning was at a moderate level in those providing care for a family member who had sustained a severe TBI. This level of function might pose difficulty regarding ability of the family towards a variety of basic, developmental and crisis tasks. The investigation suggests a future study, complementing quantitative methods with qualitative approaches.

Keywords: caring, family system functioning, severe traumatic brain injury

Contact: Sumamita Sawasdinaruenart, M.N.S.

Faculty of Nursing, Chiang Mai University, Mueang, Chiang Mai 50200, Thailand.

E-mail: sumamita.s@gmail.com

(c) 2020 JHSMR. Hosting by Prince of Songkla University. All rights reserved.

This is an open access article under the CC BY-NC-ND license

(http://www.jhsmr.org/index.php/jhsmr/about/editorialPolicies\#openAccessPolicy).
J Health Sci Med Res 2021;39(3):219-227 doi: 10.31584 /jhsmr.2021779 www.jhsmr.org 


\section{Introduction}

Traumatic brain injuries (TBI) are an important public health problem of mortality and disability among young adults worldwide. ${ }^{1}$ Each year an estimated 10 million people sustain a TBI around the world. ${ }^{2}$ In Thailand, the number of people dying, as well as the morbidity and disability, resulting from road traffic injuries has been continually increasing; greatly affecting individuals experiencing TBls, their families and society. ${ }^{3}$ There has also been an increase in the number of TBI survivors, due to advances in medical technology and care. TBI survivors encounter consequences that might last a few days, or for the rest of their lives. Severe TBI can cause some survivors in an unconscious or persistent vegetative state including impairments related to cognitive, emotional, and physical function. ${ }^{4}$ These impairments not only affect individuals, but also can have lasting effects on families and communities. ${ }^{5}$ Survivors with severe TBIs, who live with significant disability and a high level of dependence, require continuing care, which is often provided by their families after returning home. ${ }^{6}$

Each member in a family has a specific role, driving everyday family functioning to maintain it as a unit and achieve desired goals of successful achievement of a variety of basic, developmental and crisis tasks. ${ }^{7}$ When a family member sustains a severe TBI, this could affect other family members as well as alter their function, which in turn affects the whole family system functioning. The extent of family disruption as well as the strengths and weakness should be assessed for allocating family supports. ${ }^{8}$ Previous studies, conducted to assess family functioning for two and five years of a family with persons who sustained a TBI, revealed the impact on family functioning and distress in relatives even at 5 years post-injury. ${ }^{9}$ Most previous research of family functioning has been completed in Western countries. These studies investigated the impact of various types of TBI on a single family caregiver, but not from the perspective of the family unit. ${ }^{10-12}$ Further study of family systems functioning in care for individuals with TBI is necessary; particularly examining brain injuries of similar severities. Cultural differences can influence family members' perceptions of family functioning differently. Because, family functioning is socio-culturally defined, and may result in divergent attitudes towards family life, there is a need to assess differences in the functioning of families within specific cultures. ${ }^{13-14}$ In Thailand, previous studies have focused on the preparation of primary caregivers for discharge of individuals with all TBls, from the hospital setting ${ }^{15,16}$, and then short-term follow-up after discharge to two weeks. ${ }^{16}$ There have been a limited number of studies of family systems functioning in care for Thai survivors with severe TBls.

There is a growing body of evidence suggesting that family assessment is vital in determining the strengths and weakness of the whole family, in order to provide appropriate support. To our knowledge, there had been no previous research examining family system functioning as well as using the Family Assessment Measure III (FAM III) approach to describe family system function of a family with people who have sustained a severe TBI in the Thai context.

\section{Material and Methods}

A cross-sectional survey was employed at the neurosurgical outpatient department (OPD) of two, Tertiary hospitals, and at the homes of severe TBI survivors, from September, 2018 to March, 2020; in Songkhla province, Thailand.

Approval for the study was obtained from the Research Ethics Review Committee of the Faculty of Nursing, Chiang Mai University (number ID 2018-052), the Research Ethics Committee of Hatyai Hospital (ID 70 Protocol number 70/2561) and the Ethics Committee of the Faculty of Medicine, Prince of Songkla University (ID 1799 REC 62-071-19-6). Participants were given written information explaining the study purpose, procedures, 
potential risks and benefits and plans to maintain confidentiality. Participants were informed about their rights to withdraw from the study at any time, without affecting their medical care status. Participants had the opportunity to ask questions about the study during informed consent procedures. Written informed consent was obtained from all participants.

A purposive sample of family members, who were living with and providing care for severe TBI individuals from a range of three months, up to 15 years (defined by the Glasgow Coma Scale from 3 to 8 at time of admission), were recruited from OPDs. Inclusion criteria for family member samples included: having at least two members in the family aged 18 or older; being absent of previous psychiatric history, those being able to communicate in Thai and those being willing to participate in this study. Individuals were approached for participation when said individuals, with a severe TBI and their family members, came to follow up at the OPD.

The sample size was calculated from the population proportion formula: $n=Z^{2} P(1-P) / d^{2}$ where $Z$ is a level of confidence (1.96), $\mathrm{P}$ is expected proportion (if $10.0 \%$, $p$-value $=0.1) ; d$ is precision $(0.05) .{ }^{17}$ The expected proportion, based on the number of individuals with a TBI and the number of those with severe TBls, from the 2016 annual reports of two, tertiary hospitals, was expected to be a proportion of 0.07 , results from the formula were 100 family members. According to a previous study, the average number of members in a Thai family is four people. ${ }^{18}$ As the family is the unit of analysis, 25 families, including multiple members from each family were required; with and anticipated $20.0 \%$ dropout rate. ${ }^{19}$ Although, this study expected to enroll 30 families, it actually enrolled 32 families.

Family Systems Functioning was measured using the FAM-III General Scale, which is a self-report questionnaire, developed by Skinner, Steinhauer and Santa-Barbara. ${ }^{20}$
It has been used for assessing family functioning based on the Process Model of Family Functioning that focuses on the family as a whole unit. The questionnaire consists of 50 statements, with each statement being rated on a 4-point scale; ranging from strongly agree (3) to strongly disagree (0). The FAM-III results cover an overall score as well as seven subscales: Task accomplishment (the family's ability to resolve problems, identify tasks and respond to crises); Role performance (role integration, definition and adaptation throughout the life cycle); Communication (mutual understanding and ability to clarify misunderstandings); Affective expression (the inhibition, intensity and timing of affective communication); Involvement (the quality and degree of family members' connectedness and involvement with one another); Control (patterns of influence, flexibility and decision-making); Value and norms (the degree of agreement between components of the family's value system, and the degree of concordance with the culture to which the family belongs). Additionally, two response-style subscales are also generated; including Social Desirability (SD) and Defensiveness (D), which evaluate the validity of the protocol level of profile distortion. ${ }^{20}$

According to the manual, raw scores for each subscale are transformed into $\mathrm{T}$-scores, before averaging the General Scale. The General Scale is an overall rating of a family member's perception of family functioning; wherein, it is the mean of the T-scores obtained for the seven subscales. Because families are seen as the unit of analysis, the Family System Mean Score is calculated from the mean of the FAM III General Scale of all family respondents. ${ }^{20}$ The FAM-III has demonstrated both reliability and validity in discriminating families with problems. Cronbach's alpha was reported as 0.93 for the General Scale, and 0.65-0.87 for the sub-scales. ${ }^{10}$ Due to the FAM III General Scale not being available in the Thai language, before deployment in this study, it was first translated into Thai and then back translated to English, permission to both translate and use 
the FAM III General Scale was granted from the developer (personal communication, Harvey Skinner, 29, November, 2017) using World Health Organization guidelines, by two bilingual experts. ${ }^{21}$ The validity testing of the Thai version Scale was pilot-tested with 10 family members, presenting a reliable result in terms of consistency for overall General Scale $(\alpha=0.86)$, and for seven subscales were 0.61-0.89.

Following written informed consent, the demographic and health related questionnaire was developed to collect demographic variables. Each family member completed the demographic data of STBI survivors and family data, and then completed the Thai FAM-III General Scale by themselves. The researcher read the questionnaire to some family members, if they requested assistance.

Descriptive statistics were used to describe the sample and family functioning, so as to include; frequency, percentage, mean, standard deviation and T-scores. Data were analyzed using the Statistical Package for the Social Sciences 13.0 statistical package.

\section{Results}

Thirty-two families of survivors of severe TBI (22 males, 10 females) participated in the study. The mean age of the people with severe TBls was 45.8 years (range=7-85 years). The majority were Buddhist (96.9\%), married (43.8), and were rural workers prior to injury (43.8\%; Table 1). With respect to family role, $37.5 \%$ were identified as parents, $34.3 \%$ were sons or daughters and $25.0 \%$ lived with a partner's family. The mean length of time since injury was 15 months (range=3 months -15 years, S.D.=31.37; Table 1). From the 32 families, a total of 77 family members provided questionnaire data (mean number of family members per TBI survivor). The majority of the families were extended families ( $n=21,62.5 \%$ ), and had five to ten members per household $(n=17,53.1 \%)$. The majority of the samples were female $(51 ; 66.2 \%)$, married (48; 62.3\%), and Buddhist (31; 96.9\%) with high school education (19; 24.7\%). The relationships with the severe TBI survivors were adult child (24, 31.2\%), sibling (19; 24.7\%) and mother (16; 20.8\%), respectively (Table 2 ).

Table 1 Demographic characteristics of survivors with severe traumatic brain injuries $(n=32)$

\begin{tabular}{|c|c|c|}
\hline $\begin{array}{l}\text { Characteristics of survivors } \\
\text { with STBI }\end{array}$ & Number & $\%$ \\
\hline \multicolumn{3}{|l|}{ Gender } \\
\hline Male & 22 & 68.8 \\
\hline Female & 10 & 31.2 \\
\hline \multicolumn{3}{|c|}{ Age, range $=7-85$ years, mean $=45.8$ years, S.D. $=21.1$} \\
\hline \multicolumn{3}{|c|}{ Religion } \\
\hline Buddhism & 31 & 96.9 \\
\hline Muslim & 1 & 3.1 \\
\hline \multicolumn{3}{|l|}{ Marital status } \\
\hline Single & 10 & 31.2 \\
\hline Married & 14 & 43.8 \\
\hline Divorced/widowed & 8 & 25.0 \\
\hline \multicolumn{3}{|l|}{ Occupation before injury } \\
\hline Student & 4 & 12.5 \\
\hline Rural worker & 14 & 43.8 \\
\hline Business owner & 1 & 3.1 \\
\hline Agriculture & 11 & 34.4 \\
\hline Unemployed & 2 & 6.2 \\
\hline \multicolumn{3}{|l|}{ Family role } \\
\hline Mother & 5 & 15.6 \\
\hline Father & 7 & 21.9 \\
\hline Spouse & 8 & 25.0 \\
\hline Daughter & 2 & 6.2 \\
\hline Son & 9 & 28.1 \\
\hline Sibling & 1 & 3.1 \\
\hline \multicolumn{3}{|c|}{$\begin{array}{l}\text { Time length since injury (months) range }=3-183, \text { mean }=15 \\
\text { months, S.D. }=31.37\end{array}$} \\
\hline
\end{tabular}

STBI=severe traumatic brain injury, S.D.=standard deviation

Both overall and seven-subscale family system functioning scores were analyzed, and compared to the population norm; these were then interpreted using the FAM III Administration and Scoring interpretation. ${ }^{20}$ The analysis revealed that the mean score of the General Scale was between 40 and 60, indicating neither healthy nor distressed family functioning ( $M=49.9 ;$ S.D.=9.0). The mean scores, across all seven subscales of family functioning 
of the family member samples, existed within a moderate family system functioning (Table 2). Analysis of social desirability and defensiveness were employed to scrutinize a realistically, accurate appraisal of family member samples. The mean score of social desirability and defensiveness were respectively 50.0 (S.D.=9.0) and 50 (S.D.=8.7), as displayed in Table 3. The scores indicate non-distortion of the FAM profile.

Table 2 Demographic characteristics of families $(n=32)$ and family members $(n=77)$

\begin{tabular}{|c|c|c|}
\hline $\begin{array}{l}\text { Demographic characteristics of } \\
\text { families and family members }\end{array}$ & Number & $\%$ \\
\hline \multicolumn{3}{|l|}{ Family structure } \\
\hline Extended family & 20 & $62.5^{\mathrm{a}}$ \\
\hline Nuclear family & 12 & $37.5^{\mathrm{a}}$ \\
\hline \multicolumn{3}{|l|}{ Number of members in family } \\
\hline $3-4$ & 15 & $46.9^{\mathrm{a}}$ \\
\hline $5-6$ & 2 & $37.5^{\mathrm{a}}$ \\
\hline$\geq 7$ & 5 & $15.6^{\mathrm{a}}$ \\
\hline \multicolumn{3}{|l|}{ Gender } \\
\hline Male & 26 & $33.8^{\mathrm{b}}$ \\
\hline Female & 51 & $66.2^{\mathrm{b}}$ \\
\hline \multirow{2}{*}{\multicolumn{3}{|c|}{ Age (years) range $=18-85$ years, mean $=46.36$ years, $S . D .=16.71$}} \\
\hline & & \\
\hline Single & 22 & $28.6^{\mathrm{b}}$ \\
\hline Married & 48 & $62.3^{\mathrm{b}}$ \\
\hline Widowed/Divorced & 7 & $9.1^{\mathrm{b}}$ \\
\hline \multicolumn{3}{|l|}{ Religions } \\
\hline Buddhist & 31 & $96.9^{\mathrm{b}}$ \\
\hline Muslim & 1 & $3.1^{\mathrm{b}}$ \\
\hline \multicolumn{3}{|l|}{ Education level } \\
\hline Primary school & 28 & $36.7^{\mathrm{b}}$ \\
\hline High school & 19 & $24.7^{\mathrm{b}}$ \\
\hline Vocational school & 11 & $14.3^{\mathrm{b}}$ \\
\hline Bachelor's degree & 10 & $13.0^{\mathrm{b}}$ \\
\hline Graduate school & 2 & $2.6^{\mathrm{b}}$ \\
\hline Uneducated & 7 & $9.1^{b}$ \\
\hline \multicolumn{3}{|l|}{ Relationship with survivors } \\
\hline Father & 8 & $10.4^{b}$ \\
\hline Mother & 16 & $20.8^{\mathrm{b}}$ \\
\hline Spouse & 10 & $13.0^{\mathrm{b}}$ \\
\hline Adult child & 24 & $31.2^{b}$ \\
\hline Sibling & 19 & $24.7^{\mathrm{b}}$ \\
\hline
\end{tabular}

S.D.=standard deviation, a=information of families as a unit, $\mathrm{b}=$ information of individual family members

\section{Discussion}

This study intended to describe family system functioning of Thai individuals living with a family member who had sustained a severe TBI. The findings illustrate that respondents could maintain their family system function within a moderate level. This indicates family system functioning of this samples were not indicative of disturbance or problems, as per the FAM-III.

The moderate level of family system functioning found in this study was better than the previous studies, which had lower scores. ${ }^{10-12}$ This present study is not consistent with two, other studies conducted among families with acquired brain injury members. These studies revealed significant distress in family functioning, compared to the norm, as well as family members who encountered psychological problems and needed to seek supportive services. ${ }^{10,11}$ While the study by Miro showed lower scores and relatively healthy family functioning scores, their sample included milder forms of TBls, and only included the primary caregivers, which may explain the differences seen between their study and ours. ${ }^{12}$

It is clear that the effects of severe TBls extend beyond the injured person and family members, in that it affects all levels of the family system. However, the family samples were able to maintain their system functioning, and did not experience distress in family functioning. Whilst the FAM III General Scale certainty determines whole family system functioning, it does not, however, determine individual functioning. ${ }^{7,20}$ This could be explained by the fact that the majority of families involved in this study are extended family members. Family is a cornerstone of Thai society, having great value and importance. Extended family members have a great deal of responsibility as the primary source of advice, support and supplementary resources for the nuclear family. ${ }^{22}$ Thai families have many members that allows them to share responsibilities as well as enable them to help one another to deal with difficulties encountered in caregiving and family-related tasks. ${ }^{23,24}$ 
Table 3 Frequency, percentage, mean and standard deviation of family system functioning $(n=32)$

\begin{tabular}{|c|c|c|c|c|c|}
\hline \multirow[b]{2}{*}{ FAM III General Scale } & \multicolumn{3}{|c|}{ Range } & \multirow[b]{2}{*}{ Mean (S.D.) } & \multirow[b]{2}{*}{ Level } \\
\hline & $\begin{array}{l}\text { Healthy } \\
<40 \\
\text { n (\%) }\end{array}$ & $\begin{array}{l}\text { Moderate } \\
40-60 \\
\text { n (\%) }\end{array}$ & $\begin{array}{l}\text { Distress } \\
>60 \\
\mathrm{n}(\%)\end{array}$ & & \\
\hline Family system mean score & - & $32(100.0)$ & - & $49.9(9.0)$ & moderate \\
\hline 1. Task accomplishment & $1(3.1)$ & $30(93.8)$ & $1(3.1)$ & $49.9(8.6)$ & moderate \\
\hline 2. Role performance & $1(3.1)$ & $31(96.9)$ & 0 & $50.0(8.4)$ & moderate \\
\hline 3. Communication & $1(3.1)$ & $30(93.8)$ & $1(3.1)$ & $50.0(8.7)$ & moderate \\
\hline 4. Affective expression & $1(3.1)$ & $31(96.9)$ & - & $49.8(8.3)$ & moderate \\
\hline 5. Involvement & - & $32(100.0)$ & - & $50.0(8.3)$ & moderate \\
\hline 6. Control & - & $32(100.0)$ & - & $50.0(8.8)$ & moderate \\
\hline 7. Value and norms & $1(3.1)$ & $31(96.9)$ & - & $49.8(8.4)$ & moderate \\
\hline Social desirability & - & $32(100.0)$ & - & $50.0(9.0)$ & moderate \\
\hline Defensiveness & $1(3.1)$ & $31(96.9)$ & - & $50.0(8.7)$ & moderate \\
\hline
\end{tabular}

FAM III=Family Assessment Measure III, S.D.=standard deviation

The moderate family system functioning in this study might be well supported by the majority of female family members of TBI survivors. In Thai society, Thai culture also frames attitudes towards gender roles. Beyond women's roles as a wife and mother, they are expected to take responsibility and have a lead role in taking care of any sick family member. Thai women give value to family and place a priory on the needs and supports of other family members. ${ }^{25}$ For this reason, the majority of female family members in this study could contribute to prevent the development of distressed family system functioning.

The family participants were equally distributed over three time points since injury: 3 months to 1 year, 1-2 years, and more than 2 years; however, family member respondents were consistently in the moderate level of family functioning. There was no difference between the either the overall level of family system functioning, nor severity of injury or time since injury. These findings are consistent with previous studies, using the FAM-III General Scale Scores, in samples of people with acquired brain injuries (including TBIs). ${ }^{10-12}$
In this study, the family's ability to accomplish family functions in all subscales were at the moderate level, and may be greatly influenced by norms and values of the culture. ${ }^{7}$ Specifically related to this present study are Thai cultural norms, religious beliefs, and family values. For instance; 'Bun-khun' and 'filial piety' are critical virtues underpinning Thai culture. 'Bun-khun' or grateful relationship plays a vital role in underpinning family member's response of their perceived caring roles, and responsibilities to a sick or injured member in a family. This reflected filial piety is rooted in the Thai cultural concept of Bun-khun. ${ }^{13}$ Since, a majority of samples were Buddhists and their offspring, it is notable that Buddhist philosophy reflected the beliefs of 'karma', or the law of "cause and effect”, could influence or affect their values, attitudes, and perceptions toward their roles, responsibilities or behavior patterns in caring for a sick member of the family. ${ }^{26}$ This was found, in particular, in Thai families where younger members take care of their parents, or older members with good gratitude, They also believed in making merit, which is taking care of the sick member so as to receive good things in the 
future. ${ }^{13}$ As shown in Table 2, clear, reasonable rules with the same views among family members were perceived by the majority of the family samples. This current study also shed light on strong family bonds among the family samples. The high scores of the items in communication subscales; such as being a part of their family, traditionally obedient, sticking together, closer and keeping strong relationships within their family, might indicate their solidarity and strong family bond (Table 3). From this reason, family members experienced moderate and tended to distress in some family functioning subscales, and the strengths in values and norms harmoniously compromises other weakness subscales. According to Zaker and Boostanipoor, cultural considerations are viewed as important aspects in family therapy. ${ }^{14}$ In congruence, Skinner, Steinhauer, and Sitareniosc emphasized values and norms provide the basis for processes of all seven subscales functioning. Values and norms have influences on family rules as well as attitudes and behavior of family members. The family norms are also shaped in consistence with specifics cultural contexts, ${ }^{7}$ which in turns effects the way they provide care for family members who have sustained a severe TBI. The data revealed family members experienced changes in all subscales, in particular role performance and affective expression, as seen from its minimum scores (39.7; 37.2). Extensive results, carried out on the key aspects of this argument, towards the moderate family functioning system scores could, therefore be made into a cultural context of Thais.

According to FAM III guideline interpretation: ${ }^{20}$ the more family members who indicate an elevated score in a particular subscale, the more likely that subscale is to be problematic. The different scale scores are elevated for different family members; it is evident a problem exists, but is perceived very differently by various family members. The higher score existing in the communication subscale might be argued in association with patterns of communication in Thai families. As to the aforementioned results, they revealed that the majority of the sample agreed with the argument that: generally the oldest member, or head of the family was designated as assigning tasks, and the levels of help to be given by other family members. ${ }^{13}$ These findings appear to be well substantiated by social relations within Thai society. According to Hofstede and Hofstede, Thailand is a collectivist culture as Thais place a strong emphasis on relationships, and avoid or resist anything that threatens the harmonious balance of their group or family. Additionally, they are concerned about what others think about their communication, particular within a family. ${ }^{27}$ As a result, communication and discussion is likely to be conducted in a roundabout fashion, rather than in a direct manner. ${ }^{28}$ Mutual understanding may be difficult to reach among family members. However, moderate family functioning means that family system function is less effective than the family at a healthy level. ${ }^{29}$

The present study has some limitations, as the control subscale had the lowest internal consistency $(\alpha=$ 0.61) for the overall sample. This could be explained by the meaning of this specific item within the cultural context and values of the participating Thai families. Moreover, additional context regarding the family system functioning can be provided by the FAM-III, with use of its Dyadic Relationship Scale and Self Rating Scale. It should be considered for family dynamics of Thai families in the future, so as to cover the cultural perception as well as to incorporate its strengths and weakness of family system functioning. In addition, this study only focused on the General Scale, because it is a reliable and potential tool for assessing family functioning as the whole family system.

In summary, the findings of this study could reflect the consequences and/or impacts of having a family member who has sustained a severe TBI in the family on the family system functioning at a moderate level. The findings, taken together, are encouraging and can raise awareness 
of the nurses as well as health care professionals. This may provide for the allocation of long-term interventions, or programs to support family members; to attain healthy family system functioning, for the successful achievement of the family. This study provides additional evidence that the FAM III is suitable and feasible to assess the family system functioning of TBI survivor's family in a Thai context. Future studies are recommended to identify factors that could positively affect family functioning, and to develop culturally sensitive family functioning measures, which would fit better with Thai culture and families.

\section{Conclusion}

A cross-sectional study of family functioning, in families caring for survivors with severe TBIs, was conducted. The self-report questionnaire revealed that families perceived their family functioning to be at a moderate level. Therefore, nurses have to understand family functioning in caring for STBI survivors, so as to perceive family strengths and weakness, while caring for survivors with STBI, in order to support family functioning effectively through continued care; whilst maintaining the family balance.

\section{Acknowledgement}

This study was supported by the scholarship of Prince of Songkla University and Graduate School, Chiang Mai University.

\section{Conflict of interest}

No conflict of interest related to this article is reported.

\section{References}

1. World Health Organization. Violence and injury prevention and disability (VIP): neurotrauma [homepage on the Internet]. Geneva: WHO; 2018 [cited 2020 May 20]. Available from: https://www.who.int/violence_injury_prevention/road_traffic/ activities
2. Oyesanya T, Brown RL, Turkstra LS. Caring for patients with traumatic brain injury: a survey of nurses' perceptions. J Clin Nurs 2017;26:1562-74.

3. Bureau of Epidemiology, Ministry of Public Health. Annual Epidemiological Surveillance Report [homepage on the Internet]. Nonthaburi: BOE; 2018 [cited 2020 May 14]. Available from: http://apps.boe.moph.go.th/boeeng/annual.php

4. Sherer M, Vaccaro M, Whyte J, Giacino JT. The consciousness consortium. Facts about the vegetative and minimally conscious states after severe brain injury. Houston: University of Washington/MSKTC; 2019 [cited 2018 Jun 16]. Available from: https://www.brainline.org/article/facts-about-vegetativeand-minimally-conscious-states-after-severe-brain-injury? page $=4$

5. Andelic N, Sigurdardottir S, Arango-Lasprilla JC, Alison GK. Long-term functional and psychosocial consequences and health care provision after traumatic brain injury. Behav Neurol J 2016;10:1-3.

6. Stocchetti N, Zanier ER. Chronic impact of traumatic brain injury on outcome and quality of life: a narrative review. Crit Care $\mathrm{J}$ 2016;20:1-10.

7. Skinner $H$, Steinhauer PD, Sitarenios G. Family assessment measure (FAM) and process model family functioning. J Fam Ther 2000;22:190-210.

8. Evans-Roberts C, Weatherhead S, Vaughan F. Working with families following brain injury. Rev Chil Neuropsicol 2014;9: 21-30.

9. Ponsford J, Schonberger M. Family functioning and emotional state two and five years after traumatic brain injury. J Int Neuropsych Soc 2010;16,306-17.

10. Gan C, Schuller R. Family system outcome following acquired brain injury: clinical and research perspectives. Brain Injury $\mathrm{J}$ 2002;16:311-22.

11. Gan C, Campbell KA, Gemeinhardt M, McFadden GT. Predictors of family system functioning after brain injury. Brain Injury $\mathrm{J}$ 2006;20:587-600.

12. Miro MM, Family functioning following traumatic brain injury: a cross-cultural investigation. A dissertation submitted in partial satisfaction of the requirement for the degree of doctor in psychology. Miami: ProQuest Information and Learning; 2003.

13. Wiseso W, Fongkaew W, Pinyokham N, Spiers J. Caring for terminally III persons with cancer: experiences of Thai Buddhist 
family caregivers. Pac Rim Int J Nurs Res Thail 2017;21:31730.

14. Zaker SB, Boostanipoor A. Multiculturalism in counseling and therapy: marriage and family issues. Rev Int Psicol Ter Psicol 2016;8:53-57.

15. Rukkeattiyos S, Changmai S, Hinjiranan, S. The outcomes of adjustment program of caregiver of traumatic brain injury patients at a tertiary level hospital in Petchaburi Province. TJNC 2013;62:43-51.

16. Narkthong N. Effect of Tailored discharge preparedness program on caregiver's discharge readiness in caring for patients with traumatic brain injury. Songkhla: Prince of Songkla University; 2014

17. Daniel WW. Biostatistics: a foundation for analysis in the health sciences. $7^{\text {th }}$ ed. New York: John Wiley and Sons; 1999.

18. Wongsawang N, Lagampan S, Lapvongwattana P, Bowers BJ. Family caregiving for dependent older adults in Thai families. J Nurs Scholarsh 2013;45,336-43.

19. Burns N, Grove SK. The practice of nursing research: appraisal, synthesis, and generation of evidence. $8^{\text {th }}$ ed. St. Louis, Missouri: Elsevier Saunders; 2017.

20. Skinner HA, Steinhauer PD, Santa-Barbara J. Family assessment Measure-III (FAM III) Technical Manual. Toronto: Multi Health Systems; 1995.

21. World Health Organization. Process of translation and adaptation of instruments [homepage on the Internet]. Geneva: WHO;
2018 [cited 2018 June 20]. Available from: https://www.who. int/substance_abuse/research_tools/translation/en/

22. Rattanasak D, Nantachaipan P, Sucamvang K, Moongtui W. A causal model of well-being among caregivers of people with spinal cord injury. Pac Rim Int J Nurs Res Thail 2013;17:342-55.

23. Lumprom O. Family hardiness, social support, and well-being of Thai traumatic brain injury family caregivers. Songkhla: Prince of Songkla University; 2017.

24. Prombut $P$, Piaseu N, Sakulhongsopon S. Factors related to stress of family caregivers of patients with stroke at home. Ramathibodi Nurs J 2014;20:82-96.

25. Meecharoen $W$, Sirapo-ngam $Y$, Mongkong $S$, Oratai $P$, Northouse LL. Factors influencing quality of life among family caregivers of patients with advance cancer: a causal model. Pac Rim Int J Nurs Res Thail 2013;17:304-16.

26. Hunsa S, Kane C. Caring for the seriously mentally III in Thailand: Buddhist family caregiving. Arch Psychiat Nurs 2005;19:44-57.

27. Hofstede HG, Hofstede JG. Cultures and organizations: software of the mind. New York: McGraw Hill Professional; 2005.

28. Burnard P, Naiyapatana W. Culture and communication in Thai nursing: a report of an ethnographic study. Int $\mathrm{J}$ Nurs Stud 2004:41:755-65.

29. Friedman MM, Bowden VR, Jones EG. Family nursing: research theory and practice. $5^{\text {th }}$ ed. Upper Saddle River N.J.: Prentice Hall; 2003. 